\title{
O SIGNIFICADO DA RETIRADA DO ÚTERO PARA AS MULHERES: UM ESTUDO QUALITATIVO
}

\author{
Adriana Magrin Rivera Sbroggio*, Maria José Martins Duarte Osis, Aloísio José Bedone
}

Trabalho realizado no Departamento de Tocoginecologia da Faculdade de Ciências Médicas da Unicamp e Centro de Atenção Integral à Saúde da Mulher (CAISM) da Universidade Estadual de Campinas (UNICAMP), Campinas, SP.

\author{
* Correspondência: \\ Rua José Admar Etter, 603, \\ Apto 12, Vila Marieta, \\ Campinas, SP, \\ Cep 13043-220. \\ adrianamagrin@hotmail.com
}

\begin{abstract}
RESUMO
OBjEtivos. Identificar os mitos de mulheres prestes a serem submetidas à cirurgia de histerectomia quanto ao significado da perda do útero para suas vidas.

Métodos. Realizou-se um estudo do tipo qualitativo com entrevistas semi-estruturadas em uma amostra proposital de dez mulheres que estavam hospitalizadas no período pré-operatório com indicação cirúrgica de histerectomia. Utilizou-se uma ficha de caracterização contendo informaçôes pessoais e um roteiro semi-estruturado com perguntas de partida e de aprofundamento para as entrevistas, que foram gravadas mediante autorização das mulheres. As entrevistas foram transcritas e realizou-se análise temática do conteúdo.

REsuLtados. Nas falas das mulheres, os mitos mais recorrentes em relação ao útero referiram-se à perda da feminilidade, frigidez, não ser mais a mesma, à possibilidade da mudança na imagem corporal (ficar oca, vazia, ter um buraco), à interferência na vida afetiva e sexual e à percepção do companheiro a seu respeito (senti-las ocas, frias, sem interesse sexual).

Conclusão. As mulheres apresentam mitos quanto à retirada do útero, relacionados à sua identidade social de gênero e à falta de conhecimento sobre seu corpo, os órgãos e suas funções.
\end{abstract}

UnITERMOs: Histerectomia. Mitos. Estudo qualitativo.

\section{INTRODUÇÃo}

Além de suas funções biológicas, o útero associa-se ao conceito de feminilidade, por relacionar-se ao papel reprodutor da mulher e à sua vida sexual. Isso significa que as mulheres podem ver o útero como aspecto importante da feminilidade, de maneira que a sua perda se refletirá sobre o que elas percebem como sua capacidade de fêmea, incluindo o desejo sexual e a libido. Através de atendimentos a mulheres histerectomizadas percebeu-se que elas só se dão conta da importância do útero como garantia de ser mulher após sua retirada. Com essa percepção, sofrem abalo em sua identidade feminina, porque para elas o útero simboliza a sua capacidade sexual. Com a retirada dele, a mulher passa a sentir-se diminuída, pois acredita estar incapacitada sexualmente para sentir prazer'.

Observa-se que as concepções acerca do útero estão intimamente atreladas à busca por exercer controle sobre a sexualidade da mulher, utilizando como justificativa a necessidade de preservá-lo para a maternidade, que foi vista por muito tempo como a única área em que as mulheres tinham uma missão social - a de preservar a espécie, produzindo filhos sadios. Esse enfoque pode ser observado no Brasil com bastante força ao final do século XIX e até a metade do século XX, quando começaram a ganhar evidência os movimentos de mulheres, inspirados nas lutas feministas internacionais. Apesar das mudanças provocadas por esses movimentos, não se pode desprezar a força dos conceitos historicamente aprendidos na educação e formação das mulheres, que certamente se refletem em suas perspectivas acerca do útero e de suas funções, vinculando-o à própria condição de ser mulher e de feminilidade ${ }^{2,3}$.

Portanto, é possível imaginar que a necessidade de realizar uma cirurgia para retirada do útero produza emoções conflitivas, traumáticas, de insegurança e ansiedade. Isso porque, além dos medos que tradicionalmente uma cirurgia pode despertar nas pessoas, no caso da histerectomia acrescentam-se as dúvidas e inquietudes com respeito à condição da mulher após a retirada do útero 4 .

Além disso, as possíveis indagações, dúvidas e insegurança das mulheres frente a um diagnóstico que implica a retirada do útero podem desencadear mudanças nos padrões sexuais após a histerectomia, por acreditarem que perdem o desejo sexual e lhes são retiradas partes vitalmente necessárias para sua atuação sexual. Novoa' e Anker ${ }^{5}$ observaram que mulheres nessa situação também manifestam preocupação pela possível infidelidade dos maridos, pois acreditam que eles podem deixar de vê-las como mulheres. Por outro lado, alguns homens têm medo de ferir suas mulheres durante o ato sexual, uma vez que elas não têm mais o útero. Aparecem várias fantasias no período pré-operatório, contribuindo para que as mulheres sintam-se abaladas quanto à "condição de ser mulher", uma vez que lhes será retirado o útero.

É freqüente o surgimento de idéias de sentir-se com um "buraco", frígida, "sem capacidade de dar e sentir prazer", que se relacionam ao processo psíquico de construção de mitos. Esses mitos estão atrelados a sentimentos, imagens e idéias assimiladas diante das necessidades instintivas e dos valores básicos de cada mulher. É como se houvesse 
um conjunto de idéias sobre o útero e seus significados que permanece adormecido no imaginário das mulheres, e diante da iminência da cirurgia para retirada do útero, tais idéias são despertadas e elaboradas segundo a criatividade de cada indivíduo ${ }^{6}$. Portanto, os mitos surgem mediante um fato concreto, como a histerectomia, mas são elaborados de acordo com a interpretação do imaginário de cada mulher ${ }^{7}$, frente ao que já ouviram sobre o que significa uma mulher não ter mais útero.

O surgimento de tais mitos, por sua natureza e capacidade de mobilizar as mulheres, pode afetar, inclusive, a maneira como elas vivenciam a cirurgia de histerectomia. Khastgir et al. ${ }^{7}$ relatam que a incidência de morbidez psicológica é mais alta antes dessa cirurgia, pois há reações emocionais no período pré-operatório devido à perda do útero, pois para as mulheres significa a perda de feminilidade, fim de um potencial reprodutivo e diminuição da sexualidade. A retirada do útero tem repercussões afetivas e psicológicas devido à associação feita pelas mulheres entre esse órgão e o conceito de feminilidade, ao exercício da sexualidade e à possibilidade de procriar?

Este trabalho apresenta resultados de um estudo que teve o objetivo de identificar os mitos em relação ao útero e seu significado, apresentados por mulheres prestes a submeter-se à histerectomia.

\section{Métodos}

Foi realizado um estudo do tipo qualitativo com o objetivo de identificar os mitos de mulheres prestes a serem submetidas à cirurgia de histerectomia quanto ao significado da perda do útero em relação: ao corpo, às relações afetivas e à vida sexual. Em vista do desenho do estudo, a amostra de dez mulheres foi selecionada propositalmente $^{10}$, dentre as que estavam hospitalizadas na enfermaria da ginecologia do Centro de Atenção Integral à Saúde da Mulher (CAISM), da Universidade Estadual de Campinas (Unicamp) no período pré-operatório com indicação cirúrgica de histerectomia. Os critérios de inclusão foram a idade até 55 anos e ter tido pelo menos um filho vivo. Foram excluídas mulheres com suspeita de diagnóstico de neoplasia maligna, o que poderia causar alterações no comportamento psíquico e prejudicar a homogeneidade da amostra.

A cada dia, a pesquisadora visitou a enfermaria de ginecologia do hospital e identificou as mulheres com indicação cirúrgica de histerectomia que cumpriam os critérios de inclusão e exclusão. Cada uma delas era convidada a participar da pesquisa e, em caso de aceitar, era lido com ela o Termo de Consentimento e pedia-se que o assinasse. Em seguida, realizava-se a entrevista. Para a obtenção das informações necessárias utilizaram-se dois instrumentos: uma ficha de caracterização contendo informações pessoais, e um roteiro com perguntas de partida e de aprofundamento para realizar entrevistas semi-estrutradas.

A participação das mulheres foi voluntária, mediante a assinatura de um termo de consentimento livre e esclarecido. O protocolo da pesquisa foi avaliado e aprovado pela Comissão de Pesquisa do Departamento de Tocoginecologia do CAISM e pelo Comitê de Ética em Pesquisa da Faculdade de Ciências Médicas da Unicamp.

As entrevistas foram gravadas e posteriormente transcritas. Para preservar a identidade das entrevistadas, nas transcrições, bem como neste trabalho, elas são identificadas por um nome fictício.
As transcrições das entrevistas foram conferidas pela pesquisadora, comparando-as com as gravações. Encerrado esse processo, os textos foram inseridos na íntegra no programa computacional The Ethnograph v5. $0^{\prime \prime}$, para facilitar seu processamento e análise. Com base nas orientações de Minayo ${ }^{12}$, procedeu-se à análise temática do conteúdo das entrevistas. Identificaram-se os temas significativos que emergiram das falas das mulheres, ou seja, as unidades de significado referentes aos objetivos do estudo: as funções do útero e seu significado, útero e feminilidade, útero, sexualidade e imagem corporal, relacionamento conjugal. Especialmente foram focalizados os mitos presentes no discurso das mulheres com relação à retirada do útero e suas repercussões sobre a vida sexual, as relações afetivas e conjugais.

Na amostra estudada, as mulheres tinham em média 44 anos, três filhos vivos, renda familiar em torno de 4,5 salários mínimos, e nove delas haviam estudado até a 8 a série do ensino fundamental; em sua maioria, as entrevistadas eram católicas, nove eram casadas, uma estava separada.

\section{Resultados}

\section{As funções do útero e seu significado}

A idéia mais presente nas falas das mulheres foi que a principal função do útero é gerar filhos. Uma das entrevistadas, inclusive, disse que quando o útero já não exerce suas funções biológicas ele serve para trazer doenças como a que ela tinha. As mulheres entrevistadas viam o útero como um órgão natural do seu corpo, era próprio delas "ter útero", e isto significava a possibilidade de gerar filhos. Era visto como um órgão benéfico, útil, na medida em que ele executava essa função reprodutiva. Uma mulher disse que, naquele momento, o útero já não significava mais nada, porque ia ser retirado. Apenas uma mulher disse que, além disso, o útero era responsável pelo prazer sexual da mulher.

"Agora mesmo na minha cabeça eu acho que ele não significa nada. No passado, na primeira gravidez, engravideifácil, a segunda não conseguia, foi difícil eu engravidar. Sabe aquela época ele significava muita coisa pra mim né, eu queria ter filhos, queria ter meus filhos, mas agora ele não significa mais nada" (Cristiane, 45 anos).

"O útero faz parte do corpo da mulher, né?" (Camila, 39 anos)

\section{Útero e feminilidade}

Ser mulher é ter útero; ter útero é ser feminina. Esta foi uma constante relação feita nas falas das entrevistadas. As mulheres referiram já ter ouvido dizer que a retirada do útero traria conseqüências nessa área. Apareceu a idéia de que a mulher que retira o útero não será mais a mesma e nem será mais igual às outras mulheres, e que isso poderia resultar no marido não querê-la mais, implicando uma mudança de vida. Ao falarem sobre esses comentários ouvidos de outras mulheres, em nenhum momento as entrevistadas foram claras quanto a se acreditavam ou desacreditavam totalmente do que haviam escutado. Em suas falas detecta-se, com freqüência, uma certa ambigüidade quanto ao que elas mesmas aceitavam desses comentários.

"...nervosa, preocupada porque ela não era mais mulher igual às outras, teriam que mudar a vida delas inteiramente, então sobre o marido edependendo do casamento, depende do amorque um sente pelo outro, que aquele casamento podia permanecer, sabe mais não com o contato físico como tinha antes" (Cristiane, 45 anos). 
"Isso já veio dos meus antepassados né, sempre as minhas tias, minha mãe falou isso pra mim, né? Mais as mulheres que assim tinham filhos, que não se cuidassem nas dietas, depois que precisavam tirar o útero, até o marido abandonava porque não ficava mais mulher. Mas eu sempre achei que fosse pesquisar sobre isso, quando vejo que não tem fundamento... (Cristiane, 45 anos).

\section{Útero, sexualidade e imagem corporal}

Nas falas das mulheres a idéia de sexualidade limitou-se à prática das relações sexuais. Em função disso, observou-se que elas se dividiam entre as que entendiam que a retirada do útero não alteraria esse aspecto de sua vida, e outras que tinham dúvidas a esse respeito: se a cirurgia as levaria à menopausa e precisariam tomar hormônios, quanto à perda ou aumento do prazer sexual e do interesse do parceiro por elas depois da cirurgia, se ficariam ocas e sentiriam dor durante a relação sexual. As dúvidas manifestas foram sempre referidas com base no que ouviram dizer de outras pessoas, especialmente de outras mulheres. Apesar dessas dúvidas, as mulheres, com freqüência, enfatizaram que, ainda que sua vida sexual mudasse para pior depois da cirurgia, elas não se importavam, porque "sexo não é tudo".

"...Também (sexo) não étudo mesmo. Acho que sexo não étudo. Não pra mim... Só essa minha irmã que falou que acha que depois que operou achou que ficoufaltando um pedaço, vaimodificar, não vaisentir prazer e tal, mas... eu acho que não é por aí" (Melissa, 44 anos).

Uma mulher fez referência à possibilidade de não mais sentir prazer sexual, o que, no caso dela, era uma mudança para melhor porque o marido era impotente há dez anos. Dessa forma, se a cirurgia a impedisse de sentir prazer, seria melhor porque não vivenciaria mais o seu conflito nesta área.

"É porque o útero é pra ter relação, mas eu, e meu marido infelizmente, fez uma cirurgia de coração, depois ele não teve mais relação. Sabe jáfaz uns 10 anos quase, então quer dizer, acho que não, não vai fazer tanta falta por causa disso também, mesmo assim acho que não teria problema" (Célia, 52 anos).

As referências das entrevistadas quanto a possíveis mudanças em seu corpo após a cirurgia limitaram-se também a dúvidas se elas poderiam vir a ganhar peso por terem que ingerir hormônios.

"Eu falei pra ela (amiga) assim: tanta gente já operou e disse que não é nada disso, outras falam que vaiengordar, que vaitomar hormônio tudo isso (após a cirurgia)" (Paula, $4 \mathrm{I}$ anos).

\section{Relacionamento conjugal}

De modo geral, as mulheres revelaram otimismo, esperando que sua vida melhorasse depois da cirurgia por resolverem os sintomas que as incomodavam há bastante tempo, especialmente o sangramento freqüente e excessivo. Entendiam que somente depois da cirurgia poderiam retomar suas vidas em todas as áreas, podendo voltar a desempenhar seus papéis sexuais e sociais. Porém, as mulheres manifestaram ambigüidade quanto a mudanças no relacionamento conjugal em virtude da retirada do útero. Algumas achavam que nada mudaria, enquanto outras manifestavam dúvidas quanto às relações sexuais. Para as que diziam que nada mudaria, porém, isto significava que 0 relacionamento continuaria ruim, principalmente na relação sexual, pois suas relações já se encontravam bastante conflituosas.
"Não vai mudar nada, vai continuar a mesma coisa, por causa da família né. Depois de uma idade dessa, ninguém se afirma, dá exemplo pros filhos, não posso fazer nada, tenho que dar exemplos"(Célia, 52 anos).

"Não, porque éele (marido) mesmo disse, se tudo que for pra minha saúde ele disse que vai ser bom pra vida dele também... eu não entendo sobre o colo do útero, essas coisas, ele acha que o colo do útero é que ajuda na sexualidade. Retirando o útero fica inteiramente, ah! como se diz... fica um oco que o marido que não vai ter relação, não vai ter nada lá. Sabe, você vai ficar totalmente estranho... ele também não acredita assim" (Cristiane, 45 anos).

\section{Discussão}

Os resultados apresentados indicam que as mulheres a serem submetidas à histerectomia apresentaram mitos com relação à retirada do útero. Os mais recorrentes nas falas das mulheres entrevistadas referiram-se à perda da feminilidade, frigidez, não ser mais a mesma, à possibilidade da mudança na imagem corporal (ficar oca, vazia, ter um buraco), à interferência na vida afetiva e sexual, e à percepção do companheiro a seu respeito (senti-las ocas, frias, sem interesse sexual).

Dentre esses mitos, os que estavam relacionados à sexualidade tiveram bastante ênfase nas falas das mulheres: perda da condição de ser mulher, de sua feminilidade, frigidez, mudanças na vida sexual. Embora haja autores como McCary ${ }^{13}$, que afirma que o desejo de uma mulher prossegue inalterado até por volta de seus 60 anos de idade ou mais, razão pela qual não haveria motivo para ela encerrar suas atividades sexuais como conseqüência da histerectomia, os resultados apresentados indicam que os mitos a respeito da retirada do útero podem interferir na vivência que as mulheres terão da experiência de ser histerectomizadas, e se refletirem sobre a sua vida sexual. Para compreender melhor esse achado, é preciso considerar que os mitos revelados pelas mulheres associavam-se ao entendimento de que a histerectomia, de fato, encerraria o período reprodutivo da sua vida, e isso, para elas, comprometia a sua sexualidade. Essa associação entre reprodução e sexualidade tem sido abordada na literatura em várias áreas do conhecimento, apontando-se a sua relevância para compreender como as mulheres vivenciam as mudanças em sua condição reprodutiva ${ }^{14}$.

Há de se ressaltar a submissão da sexualidade à reprodução. Do ponto de vista patriarcal, que ainda domina vários ambientes sociais, a identidade das mulheres resume-se à sua condição de reprodutoras da espécie, e o exercício de sua sexualidade somente é admitido se atrelado à realização do papel reprodutivo, em submissão ao domínio masculino, ao seu desejo ${ }^{2}$. Tradicionalmente, o corpo da mulher tem sido visto como tendo, primariamente, uma função social, a reprodução. A sua "utilidade" está dada por seu papel reprodutivo. Logo, a sexualidade desse corpo também deveria estar a serviço de seu papel social. As mulheres tendem a vivenciar a experiência de estarem presas ao seu corpo-para-outros, quer do ponto de vista procriativo, quer como elemento erótico, o que determina que elas acabem estabelecendo relações de dependência vital e de submissão $0^{15,16}$. Portanto, não é estranho que as mulheres associem a retirada do útero com possíveis problemas sexuais, bem como se sintam sob o risco de serem desvalorizadas como mulheres por causa dessa perda. 
A presença do útero no corpo era vista pelas mulheres como natural. Isso, provavelmente, fizera com que, até que se lhes apresentou a necessidade da cirurgia, nunca haviam pensado sobre o significado do útero e, menos ainda, haviam pensado a sua existência sem o útero! Veja-se, por exemplo, a relação detectada nas falas das mulheres entre a doença que tinham e a perda da função do útero. No entender delas, quando o útero deixa de reproduzir ele produz doença, sofrimento para a mulher, razão pela qual deve ser retirado. E interessante observar como as mulheres que participaram do estudo, ao serem perguntadas sobre o significado do útero para si mesmas, imediatamente evocavam a função que atribuíam a esse órgão, que era a de gerar filhos. Logo, se o útero não servia mais para gerar filhos, ele também não significaria mais nada para elas. As mulheres, portanto, apresentavam apenas uma definição funcionalista acerca do útero, que se refletia na maneira como percebiam a si próprias também como seres sociais. Nesse momento, a retirada do útero era vista como a perda de suas próprias funções, o que pode ter facilitado a assimilação de mitos que falam sobre as mulheres ficarem vazias, "ocas" depois da histerectomia. Ao mesmo tempo, a iminência da histerectomia suscitou uma série de reelaborações na auto-imagem das mulheres, no sentido de buscarem uma reconfiguração de sua identidade social.

Em que pese a natureza qualitativa do estudo realizado, que implica algumas limitações de generalização, esta discussão leva a perceber a necessidade de abordar a retirada do útero a partir de uma perspectiva de atenção integral à saúde das mulheres e no contexto de humanização do atendimento. $O$ atendimento a essas mulheres não pode ignorar o impacto que sofrerão com a notícia de que será preciso retirar o útero. É preciso que a rotina hospitalar (consulta e internação) constitua um meio favorável para as mulheres vivenciarem a histerectomia da maneira menos prejudicial possível. Isso inclui a necessidade de prover condições de atendimento em que os profissionais tenham capacitação e condições de trabalho para permitir às mulheres a assimilação das informações que irão receber, e a reflexão sobre o impacto em sua vida do diagnóstico e da conduta proposta. Interessante observar que vários autores ${ }^{1,4,17,18,19}$ mencionam o fato de as mulheres sentirem-se aliviadas com a possibilidade de retirarem o útero, com base na esperança da sobrevivência e da superação do incômodo causado pelos sintomas de sua doença. Entretanto, não se pode deixar de considerar que tal alívio está associado ao desaparecimento das dores, sangramentos e incômodos, mas não aos sentimentos das mulheres quanto ao significado da perda do útero. Certamente, elaborar esse significado requer tempo para que elas possam fazer planos frente a suas emoções ${ }^{20}$. Nesse processo, deve haver espaço para emergirem os mitos que as mulheres trazem consigo, a fim de confrontá-los com a melhor informação científica disponível. A realização de grupos de orientação, aliados ao atendimento psicológico, podem viabilizar a melhor compreensão das mulheres quanto ao seu corpo, à patologia que as aflige, ao procedimento cirúrgico que será realizado e à sua condição pós-cirúrgica ${ }^{21,22}$.

\section{Conclusão}

As mulheres que estavam prestes a submeter-se a uma histerectomia apresentaram mitos quanto ao significado do útero e das possíveis repercussões em sua vida da retirada desse órgão. Evidencia-se a necessidade de se atuar junto a mulheres nessa condição, para que tais mitos sejam confrontados com a informação científica, de maneira que lhes seja permitido vivenciar a cirurgia e o pós-operatório do modo menos inquietante e mais satisfatório.

\section{Conflito de interesse: não há.}

\section{SUMMARY}

\section{THE SIGNIFICANCE OF UTERUS REMOVAL FOR WOMEN}

OBIECTIVE. To identify the myths accepted by women about to undergo hysterectomy regarding the consequences that removal of their uterus might have on their lives.

METHODS. A sample of 10 hospitalized women with surgical indication for hysterectomy was used to perform a qualitative study, with semistructured interviews carried out during the preoperative period. A profile questionnaire was used with questions about personal features and semistructured inquiries to facilitate deeper questioning. With authorization of the subjects, interviews were recorded and transcribed to perform a thematic analysis of the content.

RESULTS. The myths most often mentioned during the interviews were: loss offemininity, frigidity, change in personality, possible change in body appearance (since they would be "hollow", "empty", "have a hole inside their belly"), interference in the affective and sexual life and the belief that their companion might change in relation to them (assuming that they would be hollow, cold, and with no sexual attraction).

CONCLUSION. The interviewed women accepted a number of myths about the consequences that removal of their uterus would have on their lives. These myths are related to the social identity of the gender and to a lack of knowledge about their body its organs and functions. [Rev Assoc Med Bras 2005; 5 I (5): 270-4]

KEY wORDS: Hysterectomy. Myths. Qualitative study.

\section{REFERÊNCIAS}

I. Novoa AM. Histerectomia: efeitos emocionais na identidade feminina. Opinião 1996;6:193-5.

2. Parker R. Corpos, prazeres e paixões: a cultura sexual no Brasil contemporâneo. $2^{a}$ ed. Tradução de Andrade MTM. São Paulo: Best Seller; 1991.

3. Heilborn ML. Gênero: uma breve introdução. In: Ribeiro NMGR, Costa DM, organizadores. Gênero e desenvolvimento institucional em ONGs. Rio de Janeiro: IBAM/ENSUR/NEMPP; I 995. p.9-| 4.

4. Cosmo M, Carvalho JWA. Pensando sobre o período pré-operatório na histerectomia. Rev Soc Bras Psicol Hosp 2000;3:27-32.

5. Anker LW. Vivências psicológicas associados à histerectomia: um enfoque psicanalítico. Rev Psicol Hosp 1993;5:20-3.

6. Zimmerman EB. Os contos de fada: expressão do desenvolvimento humano. In: Giglio JS, organizador. Contos maravilhosos: expressão do desenvolvimento humano. Campinas: Ed. Unicamp; 1991. p. $\mid$ - | | .

7. Pingaud B, Pontalis JB.Laplanche (colab). Freud. Netto C. (trad). São Paulo: Ed. Documentos; 1969.

8. Khastgir G, Studd, JWW, Catalan J. The psychological outcome of hysterectomy. Gynecol Endocrinol 2000; | 4: |32-4|

9. Angerami-Camon VA. Urgências psicológicas no hospital - as cirurgias ginecológicas: uma questão para a psicologia. São Paulo: Thomson Pioneira; 1998. 
10. Patton MQ. Qualitative evaluation and research methods. In: Patton MO. Designing qualitative studies. $2^{\text {nd }}$ ed. California: Sage; 1990. p. | 45-98.

I I. Seidel J. The ethnograph [computer program]. Version 5.0. Salt Lake: Qualis Research Associates; 1998.

12. Minayo MCS. O desafio do conhecimento: pesquisa qualitativa em saúde. 2a ed. São Paulo: Hucitec; 1993.

13. McCary JL. Mitos e crendices sexuais. São Paulo: Manole; 1978.

14. Osis, MJMD. Laqueadura e representações Acerca da sexualidade e do papel reprodutivo [tese]. Campinas: Faculdade de Ciências Médicas, Universidade Estadual de Campinas; 200 I.

15. Carson AC. Entrelaçando consensos: reflexões sobre a dimensão social da identidade de gênero da mulher. Cadernos Pagu 1995;4: 187-218.

16. Calderón VP. Yo (no) soy. Tú eres. Él es. La sexualidad de mujeres polisintomáticas de sectores empobrecidos desde la perspectiva de los servicios de atención primaria de salud. In: Gogna M, organizador. Feminidades y masculinidades. Estudios sobre salud reproductiva y sexualidad en Argentina, Chile y Colombia. Bueno Aires: Cedes - Centro de Estudios de Estado y Sociedad; 2000. p.23-74

17. Hufnagel V, Golant SK. No more hysterectomies. In: Hufnagel V, Golant SK. Why is the uterus important? New York: A Plume Book; 1989. p.8I-90.
18. Naughton MI, Mcbee WL. Qualidade de vida relacionado à saúde póshisterectomia. Grupo Editorial Moreira Jr. 1997;40:947-57.

19. Penteado SRL, Fonseca AM, Bagnolo VR, Abdo CHN. Sexualidade no climatério e na senilidade. Ginecol Obstet 2000; | I : | 88-92.

20. Maldonado MT, Canella P. A relação médico-cliente em ginecologia e obstetrícia. 2a ed. São Paulo: Roca; 1988.

21. Scheeffer R. Aconselhamento psicológico: teoria e prática. 7ª ed. São Paulo: Atlas; 1993.

22. Chiattoni HBC. A ética em psicologia hospitalar. In: Angerami-Camon VA (org). A ética na saúde. São Paulo: Thomson Pioneira; I 997. p. I 13-40.
Artigo recebido: 12/05/04

Aceito para publicação: 10/09/04 